\title{
Impact of COVID-19 on the exercise habits of Pennsylvania residents and their families
}

\author{
Lacey N. Wallace ${ }^{1}$ (D) \\ Received: 18 December 2020 / Accepted: 21 June 2021 \\ (C) The Author(s), under exclusive licence to Springer-Verlag GmbH Germany, part of Springer Nature 2021
}

\begin{abstract}
Aim This study investigated how COVID-19 impacted the physical activity and sports participation of Pennsylvania residents and their children.

Subject and methods Data were collected through an online survey of 525 Pennsylvania residents with a child between the ages of 3 and 17. Data were collected in October 2020.

Results Nearly a third of respondents reported a decrease in their physical activity. Hispanics were more likely than nonHispanics to report a decrease in their physical activity. Older children were more likely to have a decrease in physical activity. Children in homes with more children present were less likely to see such a decline. Men were more likely than women to see COVID-19 as a barrier to physical activity for themselves and their child.

Conclusions The results of this study underscore the profound impact of the COVID-19 pandemic on our health as a nation. Exercise, in all forms, plays a key role in overall health, weight, and disease resistance. It remains unclear how declines in physical activity might persist over time, and among whom.
\end{abstract}

Keywords COVID-19 $\cdot$ Exercise $\cdot$ Sports $\cdot$ Gender $\cdot$ Ethnicity $\cdot$ Socioeconomic status

\section{Introduction}

Each year, the Bloomberg Global Health Index ranks countries worldwide on overall health, considering factors such as life expectancy, rates of disease, and environment. The U.S. consistently ranks very poorly. In 2019, the U.S. was tied with Lithuania as the 10th most unhealthy country ranked on the index (Meszaros 2019). A key reason for this placement was obesity. Adult obesity in the U.S. increased steadily since the 1970 s to its $2017-2018$ prevalence of $42.4 \%$ (Hayles et al. 2020). Rates of obesity are even higher among racial and ethnic minorities as well as those with lower socioeconomic status. These trends are not isolated to adults. In 2015-2016, $18.5 \%$ of youth ages $2-19$ had obesity, up from $13.9 \%$ in 1999-2000 (Hayles et al. 2017).

Exercise is a key factor associated with health and body weight. Specifically, exercise is associated with weight loss,

Lacey N. Wallace

LNO106@psu.edu

1 Department of Criminal Justice, Penn State Altoona, 101G Cypress Building, 3000 Ivyside Park, Altoona, PA 16601, USA maintained weight loss, and can help offset the negative health impacts of obesity even among those who remain obese (Petridou et al. 2019). The Physical Activity Recommendations for Americans, 2nd edn, urges adults to engage in 150 to $300 \mathrm{~min}$ of moderate-intensity exercise, 75 to $150 \mathrm{~min}$ of high-intensity exercise, or some combination of the two each week (Piercy et al. 2018). As of 2016, approximately $80 \%$ of adults in the U.S. failed to meet these minimum recommendations (Piercy et al. 2018).

The impact of COVID-19 on exercise patterns remains unclear. Some research found that adults exercised less during the pandemic than before (Mutz and Gerke 2021). Other work found that those who exercised very little before the pandemic increased their level of physical activity while those who were more active tended to maintain their level of physical activity (Brand et al. 2020). This study examines how COVID-19 affected family exercise and sports participation in Pennsylvania specifically. Similar to many U.S. states, Pennsylvania shut down gyms and other indoor exercise facilities in March 2020. Most sporting events were cancelled through at least Fall 2020. Unemployment across the state spiked as all but businesses considered essential were closed. Most childcare facilities and schools closed statewide. 
Outdoor playgrounds were also closed though public parks and many other outdoor recreational facilities remained operational. This study explores how changes such as these influenced Pennsylvania families.

\section{Typical patterns of activity}

Identifying change in family exercise and sports participation would be incomplete without discussion of typical patterns in these activities. According to the Physical Activity Council (2020), $73.2 \%$ of Americans ages 6 and older participated in some form of sport or exercise in 2019. This percentage was stable from 2014 to 2019. While the highest rates of participation occurred among those ages 18 to 24 , the percentage of those engaging in some sort of physical activity generally increased with age (Physical Activity Council 2020). Most children, similar to adults (Piercy et al. 2018), do not meet minimum physical activity guidelines. The 2016 Shape of the Nation report observed that less than half of children ages 6 to 11 engaged in the recommended $60 \mathrm{~min}$ of physical activity per day; that percentage dropped to $8 \%$ among those ages 12 to 19 . Very few states have minimum standards for the amount of time students should participate in physical activity (SHAPE America 2016).

Yet, schools play a key role in youth sports participation. During the 2014-2015 school year, the National Federation of State High School Associations (2016) determined that nearly 8 million youth nationwide participated in sports organized by their high schools. Pennsylvania had the 6th highest count of participants, at more than 319,000 (2016). In total, $64 \%$ of 8 th graders, $61 \%$ of 10 th graders, and $58 \%$ of 12 th graders participated in school sports nationwide in 2014 (ChildTrends 2017); these figures have remained fairly consistent over the past decade.

\section{Gender, race, and SES}

Patterns in exercise and sports participation vary substantially by social status, race, and gender. Among U.S. adults in homes earning less than $\$ 30 \mathrm{~K}$ a year, $12 \%$ reported regularly wearing a smartwatch or fitness tracker to monitor their physical activity and health in 2019; that figure was $31 \%$ among those living in homes earning $\$ 75 \mathrm{~K}$ or more (Vogels 2020). Females were more likely to track their physical activity than males although males were more physically active overall. This gender difference extends to youth. Nearly $20 \%$ of females ages 13 to 17 were inactive in 2019 compared to $14 \%$ of males in the same age group (Centers for Disease Control and Prevention 2018). Across ages, those in lower income households are much less active than those in higher earning households. In 2019, 45\% of those in homes earning less than \$25 K were inactive (no sports, no physical activity) compared to $16.5 \%$ of those in homes earning $\$ 100 \mathrm{~K}$ or more (Physical
Activity Council 2020). Black and Hispanic individuals are generally less physically active than White individuals though more likely to work in occupations that require strenuous physical activity (He and Baker 2005). These racial differences are linked, at least in part, to higher rates of individual and neighborhood poverty among Black and Hispanic people (Hawes et al. 2019).

Significant demographic gaps persist in school-based sports participation among youth as well. Males are more likely to participate in sports than females (National Federation of State High School Associations 2016; ChildTrends 2017). Participation is also much more likely for youth from higher income families. According to one study, only approximately a third of youth from families earning less than $\$ 25,000$ per year participated in a team sport on at least one day in 2016 (Aspen Institute 2017). For families making $\$ 100,000$ or more, that figure was more than $68 \%$ (Aspen Institute 2017). The same trend holds for parental education. Youth with more educated parents were substantially more likely to participate in sports in 2013; the gap in participation was roughly $20 \%$ between youth with college educated parents and youth whose parents had not completed high school (ChildTrends 2017). Pennsylvania data from the 2017 High School Youth Risk Behavior Survey also indicated that Hispanic teens ages 13 to 17 were less likely to participate in a school sports team than White individuals (Centers for Disease Control and Prevention 2018).

\section{Expected COVID-19 impact}

There are several ways COVID-19 may impact exercise and sports participation. Fear of COVID-19 transmission may have dissuaded some families from participating in sports or exercise with others (Choi and Bum 2020). With schools closed, there were fewer opportunities for sports among youth. Loss of childcare may take away from available leisure time for parents and certain activities may be more difficult with infants or young children present (Poulain et al. 2021). Single parents, especially, may not have another adult available to help care for dependent children when childcare is unavailable. However, parents and caregivers may also seek out exercise and sports opportunities as part of childcare or as a way to spend time with family members. With many other options for entertainment unavailable, such as movie theaters, exercise and sports may be a more viable option. Loss of income, however, may limit a family's ability to pay for equipment, fees, travel, and other related costs. Stress associated with job loss, illness, and other lifestyle changes may also lead to changes in physical activity (Stults-Kolehmainen and Sinha 2014). To date, it remains unclear whether the pandemic was associated with increases or decreases in exercise and sports participation, and among whom. 
The COVID-19 pandemic had disproportionate impacts based on gender, race, and social class. More women than men lost their jobs due to pandemic-related business closures and layoffs (Karageorge 2020). This was partially because women were more concentrated in industries, such as restaurant service, that were more negatively impacted by the pandemic. Further, many childcare facilities and schools closed forcing some parents to stay home to care for their children. This tendency was more common among women, who are also the primary child caregivers in the U.S. (Karageorge 2020). Similar to women, racial and ethnic minorities as well as those with lower educational attainment were more likely to lose their jobs as a result of the pandemic (Day et al. 2020). Due to these trends, this study explores how changes in exercise and sports participation varied by gender, race, and social class.

\section{Data}

Data for this study were obtained from a 100-item online survey designed by the author titled Athletics and Parenting. Topics addressed by the survey included parents' history of exercise and sports participation, parent reports of child exercise and sports participation, and perceived barriers to exercise and sports, among others. Part of the survey had respondents answer questions about each of their children. Only responses regarding the oldest/ only child are considered in this study. The survey was administered in October 2020. All survey procedures were vetted and approved by an Institutional Review Board prior to administration. The author has no conflicts of interest to report.

The Qualtrics survey research company was contracted by the author to both locate respondents and administer the survey to those respondents. Qualtrics maintains and works with market research panels consisting of more than six million individuals across the U.S. Members of these panels complete surveys in exchange for points, sky miles, and gift cards provided directly by Qualtrics. No additional compensation was offered by the author. Eligible respondents were Pennsylvania residents with the following characteristics: age 18 or older, English-speaking, non-institutionalized, parent or legal guardian of a child ages 3 to 17 and reside at least part-time with their child ages 3 to 17 . Potential respondents were first asked a set of demographic questions to assess eligibility. Quotas ensured the final sample would be representative of Pennsylvania demographics based on 2019 U.S. Census figures for gender, race and ethnicity, rural residence, and income. Once a given demographic category was represented in proportion to the Pennsylvania population (rural residents, for example), no more respondents from that demographic category were permitted to participate in the study.

Eligible respondents were shown an informed consent document. Only consenting respondents were directed to the core survey. Participants indicated their consent to proceed with the survey by selecting yes to the statement, "I have read the informed consent document and agree to participate of my own free will in this study." The target sample size for this study was 500. A rudimentary power analysis (Rosner 2015) indicated that a sample size of at least 500 was necessary to detect an 8 to $10 \%$ difference in physical activity from the $73 \%$ of Americans who identified as physically active before the pandemic (Physical Activity Council 2020). Past work with German residents found that more than $30 \%$ of adults changed their physical activity patterns as a result of COVID-19 (Mutz and Gerke 2021). In total, 5051 Qualtrics panelists were invited by email to take the survey, 2836 individuals entered the survey, 1729 respondents were either ineligible or failed a data quality check (i.e. missed an attention check question), and 584 respondents tried to take the survey after their demographic quota had already been filled so they could not take the survey. These steps resulted in a final sample of 525. Respondents took an average of $26 \mathrm{~min}$ to complete the survey.

\section{Measures}

COVID-19 impact The impact of COVID-19 on self and family activity is the dependent variable in this study. It was assessed in three ways: perceived changes in frequency of parent and child physical activity over time, change in frequency of parent and child exercising together, and perception of COVID19 as a barrier to parent or child participation.

The survey asked respondents how they felt COVID-19 impacted their own and their child's physical activity patterns. To assess perceived personal impact, respondents were asked "How did your activity level change, if at all, during the peak of the COVID-19 crisis (March through July 2020)?" Response options were "I was more physically active during the crisis than before," "I was less physically active during the crisis than before," and "my physical activity did not change as a result of the crisis." At the time the survey was administered, the second spike in cases that occurred in late $2020 \mathrm{had}$ not yet occurred. The survey question focused on the child asked "How, if at all, was this child's physical activity affected during the peak of the COVID-19 crisis (March through July 2020)? Please select all that apply." Answer options included: they had to stop playing a sport, their physical activity decreased, they started playing a new sport, they started participating in a new type of exercise, I spent more time exercising with them, I spent more time playing sports with them, their physical activity increased, and they spent more time outside. These survey questions were used to create two binary indicators: parent decreased activity ( 1 if yes, 0 if no), child decreased activity ( 1 if yes, 0 if no).

The survey also asked how often parents exercised with their children and whether this changed over time. Respondents were asked: "Do you and this child exercise together?" with answer choices of never (0), less often than 
once a month (1), once a month, a few times a month, once a week, 2-3 times a week, 4-6 times a week, and daily (8). A follow-up question asked "How, if at all, has this changed as a result of the COVID-19 pandemic?" Response options were "I exercise with my child more than I used to," "I exercise with my child less than I used to," and "no change". The latter question was used to create a binary indicator of whether parent-child exercise frequency decreased (1 if yes, 0 if no).

Respondents were asked about barriers to participation, both for themselves and their children. Regarding personal barriers, the survey asked "Do you feel that any of the following limit your own exercise or participation in sports? Please check all, if any, that apply." The COVID-19 pandemic was among the items listed. Regarding perceived child barriers to participation, the survey asked "Do you feel that any of the following limit this child's participation in sports or exercise? Please check all, if any, that apply." The COVID-19 pandemic was among the items listed. These survey questions were used to create two binary indicators: parent perceived COVID-19 as a personal barrier ( 1 if yes, 0 if no) and parent perceived COVID-19 as a child barrier ( 1 if yes, 0 if no).

Demographics Demographic characteristics were the independent variables in this study. These included parent and child gender (male, female), number of children in the home, parent and child age in years, parent race (White, Black, other race), parent ethnicity (Hispanic, non-Hispanic), parent marital status (currently married or cohabiting, not currently married or cohabiting), typical (not COVID-impacted) annual household income (under $\$ 20 \mathrm{~K}, \$ 20 \mathrm{~K}-\$ 29,999$, \$30 K-\$39,999, ..., $\$ 110 \mathrm{~K}+$ ), and whether respondent lived in a rural area (yes/ no). Respondents self-identified whether they lived in a rural area.

\section{Plan of analysis}

All dependent variables are dichotomous. Logistic regression was used to estimate associations with demographic characteristics. Odds ratios are shown in tables. An odds ratio greater than 1 indicates that a given demographic trait was associated with greater odds of a decrease in activity, decrease in parentchild exercise, or a greater likelihood of reporting COVID-19 as a barrier, respectively. All models were calculated with robust standard errors. Household income was treated as a continuous predictor variable.

\section{Results}

\section{Sample characteristics}

Sample characteristics are shown in Table 1. By design, potential participants in the study were selected such that the resulting sample would be representative of Pennsylvania demographics in 2019 (U.S. Census Bureau 2019). Even so, there were some deviations from typical Pennsylvania residents. There were more females represented in the sample $(57 \%)$ than males $(43 \%)$. White individuals were slightly overrepresented in the sample at $84 \%$ compared to the proportion White in the Pennsylvania population (82\%) (U.S. Census Bureau 2019). The proportion of the sample identifying as Black (11\%) mirrored the Pennsylvania population closely. Hispanics were underrepresented in the sample at $3 \%$ compared to $8 \%$ in Pennsylvania overall (U.S. Census Bureau 2019). Approximately a quarter of the sample lived in a rural area. Median income in the sample was in the $\$ 60 \mathrm{~K}$ $\$ 69,999$ range.

Table 1 Sample characteristics $(n=525)$

\begin{tabular}{|c|c|c|c|}
\hline Ordinal/ continuous measures & $\mathrm{N}$ & Mean (SD) & Range \\
\hline Child age & 525 & $11.14(3.87)$ & $(3,17)$ \\
\hline Parent age & 525 & $39.76(9.12)$ & $(18,75)$ \\
\hline Number of children & 525 & $2.09(1.08)$ & $(1,7)$ \\
\hline Categorical measures & $\mathbf{N}$ & Proportion & $95 \% \mathrm{CI}$ \\
\hline Parent decreased activity & 168 & $32.00 \%$ & $(0.28,0.36)$ \\
\hline Child decreased activity & 157 & $29.90 \%$ & $(0.26,0.34)$ \\
\hline Parent-child exercise decreased & 78 & $14.86 \%$ & $(0.12,0.18)$ \\
\hline COVID-19 as personal barrier & 247 & $47.05 \%$ & $(0.43,0.51)$ \\
\hline COVID-19 as child barrier & 299 & $56.95 \%$ & $(0.53,0.61)$ \\
\hline Child male & 317 & $60.38 \%$ & $(0.56,0.64)$ \\
\hline Parent male & 224 & $42.67 \%$ & $(0.38,0.47)$ \\
\hline Lives in rural area & 133 & $25.33 \%$ & $(0.22,0.29)$ \\
\hline Hispanic & 12 & $2.29 \%$ & $(0.01,0.04)$ \\
\hline Race: White & 439 & $83.92 \%$ & $(0.80,0.87)$ \\
\hline Black & 58 & $11.05 \%$ & $(0.09,0.14)$ \\
\hline Other race & 28 & $5.33 \%$ & $(0.04,0.08)$ \\
\hline Income: $<\$ 20 \mathrm{~K}$ & 81 & $15.43 \%$ & $(0.13,0.19)$ \\
\hline$\$ 20 \mathrm{~K}-\$ 29,999$ & 39 & $7.43 \%$ & $(0.05,0.10)$ \\
\hline$\$ 30 \mathrm{~K}-\$ 39,999$ & 40 & $7.62 \%$ & $(0.06,0.10)$ \\
\hline$\$ 40 \mathrm{~K}-\$ 49,999$ & 46 & $8.76 \%$ & $(0.07,0.12)$ \\
\hline$\$ 50 \mathrm{~K}-\$ 59,999$ & 48 & $9.14 \%$ & $(0.07,0.12)$ \\
\hline$\$ 60 \mathrm{~K}-\$ 69,999$ & 36 & $6.86 \%$ & $(0.05,0.09)$ \\
\hline$\$ 70 \mathrm{~K}-\$ 79,999$ & 27 & $5.14 \%$ & $(0.04,0.07)$ \\
\hline$\$ 80 \mathrm{~K}-\$ 89,999$ & 33 & $6.29 \%$ & $(0.04,0.09)$ \\
\hline$\$ 90 \mathrm{~K}-\$ 99,999$ & 31 & $5.90 \%$ & $(0.04,0.08)$ \\
\hline$\$ 100 \mathrm{~K}-\$ 109,999$ & 26 & $4.95 \%$ & $(0.03,0.07)$ \\
\hline$\$ 110 \mathrm{~K}+$ & 118 & $22.48 \%$ & $(0.19,0.26)$ \\
\hline Marital status: Single & 83 & $15.81 \%$ & $(0.13,0.19)$ \\
\hline Married or cohabiting & 387 & $73.71 \%$ & $(0.70,0.77)$ \\
\hline Other marital status & 55 & $10.48 \%$ & $(0.08,0.13)$ \\
\hline
\end{tabular}

SD refers to standard deviation. CI refers to confidence interval. $\mathrm{N}$ refers to the count for a particular response category for categorical measures and for total number of responses for ordinal and continuous measures 
In regard to COVID-19, nearly a third, $32 \%$, of parents reported that they, personally, experienced a decrease in their physical activity as a result of the pandemic. Approximately $30 \%$ reported that their child (or oldest child if they had multiple children) had a decrease in physical activity. Some families exercise together. In this study, $15 \%$ of parents reported that they exercised with their child less often as a result of the pandemic. In total, $47 \%$ of respondents felt that COVID-19 was a barrier to their physical activity or sports participation. More, 57\%, reported that COVID-19 was a barrier for their child.

\section{Demographic variation in COVID-19 impact}

Table 2 displays the results of logistic regression models predicting changes in physical activity as a result of the pandemic as well as whether parents perceived the pandemic as a barrier to physical activity for themselves or their child. In all models, White was the reference category for race and single was the reference category for marital status. There were few instances of variation in these outcomes by demographic characteristics. Regarding parents' physical activity, Hispanics were 3.7 times more likely than non-Hispanics to report a decrease in physical activity due to the pandemic.

In the second model in Table 2, focusing on child physical activity patterns, the odds of experiencing a drop in physical activity increased by 1.07 times for every year of age. In other words, older children were more likely to experience a decline in physical activity. In contrast, every additional child in the household was associated with a $21 \%$ decrease in the odds of a drop in physical activity. Children in larger households were less likely to reduce their physical activity during the pandemic. There was no significant demographic variation in the third model predicting change in parent-child exercise frequency.

There were several instances of demographic variation in the last two models in Table 2. These two models predicted perceptions of COVID-19 as a personal barrier to a respondent's physical activity or as a barrier to their child's physical activity, respectively. In the model predicting perceptions of a personal barrier, older respondents were less likely than younger respondents to see COVID-19 as a barrier to activity. Each year of age was associated with a $3 \%$ decrease in the odds of seeing COVID-19 as a barrier. Males, however, were 3.13 times more likely than females to perceive COVID-19 as a personal barrier. In the last model, males were 2.39 times more likely than females to note COVID-19 as a barrier to their child's physical activity. In both of the last two models, rural residents were less likely than others to see COVID-19 as a barrier. In the last model specifically, rural residents were nearly half (46\%) as likely as others to feel that COVID-19 limited their child's physical activity.

\section{Discussion}

While the COVID-19 pandemic affected all or nearly all U.S. residents in some way in 2020, the pandemic had disproportionate impacts based on gender, race, and social class in areas such as employment and childcare (Day et al. 2020; Karageorge 2020). This study explored how COVID-19 affected exercise and sports participation patterns among Pennsylvania residents and their children. It was expected that

Table 2 Logistic regression models predicting changes in activity and perceptions of COVID-19 as a barrier to activity $(\mathrm{n}=525)$

\begin{tabular}{|c|c|c|c|c|c|c|c|c|c|c|c|c|c|c|c|}
\hline \multirow[t]{2}{*}{ Child age } & \multicolumn{3}{|c|}{ Parent less active } & \multicolumn{3}{|c|}{ Child less active } & \multicolumn{3}{|c|}{ Parent-child exercise decreased } & \multicolumn{3}{|c|}{ COVID-19 as parent barrier } & \multicolumn{3}{|c|}{ COVID-19 as child barrier } \\
\hline & 0.98 & & $(0.03)$ & 1.07 & $*$ & $(0.03)$ & 1.05 & & $(0.04)$ & 1.03 & & $(0.03)$ & 0.98 & & $(0.03)$ \\
\hline Parent age & 0.99 & & $(0.01)$ & 1.00 & & $(0.01)$ & 0.97 & & $(0.02)$ & 0.97 & $*$ & $(0.01)$ & 0.99 & & $(0.01)$ \\
\hline Child male & 0.88 & & $(0.18)$ & 1.15 & & $(0.25)$ & 0.77 & & $(0.21)$ & 1.14 & & $(0.23)$ & 0.93 & & $(0.18)$ \\
\hline Parent male & 0.86 & & $(0.21)$ & 1.20 & & $(0.29)$ & 1.41 & & $(0.46)$ & 3.13 & $* *$ & $(0.73)$ & 2.39 & $* *$ & $(0.54)$ \\
\hline Lives in rural area & 0.89 & & $(0.21)$ & 0.69 & & $(0.17)$ & 0.65 & & $(0.22)$ & 0.68 & + & $(0.16)$ & 0.54 & $* *$ & $(0.12)$ \\
\hline Income & 0.94 & + & $(0.03)$ & 0.99 & & $(0.04)$ & 0.95 & & $(0.04)$ & 1.05 & & $(0.03)$ & 0.97 & & $(0.03)$ \\
\hline Black & 1.07 & & $(0.33)$ & 1.28 & & $(0.43)$ & 1.33 & & $(0.53)$ & 1.59 & & $(0.51)$ & 0.96 & & $(0.31)$ \\
\hline Other race & 0.71 & & $(0.35)$ & 0.69 & & $(0.34)$ & 2.87 & + & $(1.61)$ & 1.63 & & $(0.81)$ & 1.08 & & $(0.52)$ \\
\hline Hispanic & 3.72 & $*$ & $(2.49)$ & 1.98 & & $(1.41)$ & 3.52 & & $(2.77)$ & 1.42 & & $(1.04)$ & 1.02 & & $(0.72)$ \\
\hline Married & 0.86 & & $(0.26)$ & 1.35 & & $(0.45)$ & 0.79 & & $(0.30)$ & 1.01 & & $(0.34)$ & 1.55 & & $(0.47)$ \\
\hline Other marital status & 1.13 & & $(0.43)$ & 1.48 & & $(0.63)$ & 0.36 & + & $(0.22)$ & 1.48 & & $(0.62)$ & 1.56 & & $(0.60)$ \\
\hline Number of children & 1.06 & & $(0.09)$ & 0.79 & $*$ & $(0.08)$ & 1.07 & & $(0.12)$ & 0.88 & & $(0.08)$ & 0.88 & & $(0.08)$ \\
\hline Constant & 1.24 & & $(0.66)$ & 0.26 & $*$ & $(0.15)$ & 0.52 & & $(0.39)$ & 1.10 & & $(0.56)$ & 2.38 & + & $(1.23)$ \\
\hline Pseudo R-squared & 0.03 & & & 0.03 & & & 0.07 & & & 0.10 & & & 0.06 & & \\
\hline
\end{tabular}

$* * p<0.01 . * p<0.05 .+p<0.10$. Standard errors in parentheses 
sports and exercise would also be impacted differently based on a person's gender, race, ethnicity, or social status. The results of this study show that, with a few notable exceptions, this was not the case. While nearly a third of respondents reported a decrease in their physical activity, these decreases spanned across genders, races, and social classes.

One deviation from this pattern was that Hispanics were much more likely than non-Hispanics to report a decrease in their physical activity. It may be that this result was an artifact of a small sample. However, there are other possible explanations. In 2020, Hispanics were more likely to become ill and die from COVID-19 than White and other racial/ethnic groups (Calo et al. 2020). Hispanics were more likely than nonHispanic White individuals to work in occupations considered essential such as grocery stores, sanitation, and food service (Calo et al. 2020). These occupations are not conducive to telecommuting, further elevating risk. Hispanics were much more fearful of COVID-19 than other racial or ethnic groups (Pew Research Center 2020). Fear of contracting COVID-19 may have contributed to reduced physical activity. Some Hispanics may have faced language barriers or immigration concerns not encountered to the same degree by other racial or ethnic groups.

However, racial and ethnic differences did not extend to decreases in child physical activity or decreases in how often parents exercised with their children. The only distinguishing factors for child activity were child age and number of children in the home. Older children were more likely to experience a decrease in physical activity. Children in homes with more children present, however, were less likely to see such a decline. Since physical activity participation increases with age (Physical Activity Council 2020), older children may have been more likely to participate in school-sponsored sports and other activities that were suspended when schools and facilities closed. Older teens tend to spend more time with sameage peers than younger children (Lam et al. 2012). With social distancing measures in place, previous activities involving sports or physical activity may have become less feasible. Older children may also face difficulties with remote learning during the pandemic. Although some youth thrived online, others struggled with the time commitment and reduced oneon-one time with instructional staff (Dynarski 2018).

Decreases in physical activity were less likely in multichild homes. Social distancing guidelines did not apply or extend to those within one's own home in most cases. That meant that siblings could continue to play and interact together, both in physical activity and in other ways. This difference may explain why those with other children in the home were less likely to decrease their physical activity during the pandemic. Furthermore, loss of other entertainment options, such as movie theaters, may have increased the amount of time siblings normally would spend together.
While there were no differences between genders in whether physical activity decreased as a result of the pandemic, there were substantial gender differences in perceptions of the pandemic as a barrier to physical activity and sports participation. One contributing factor may be that, pre-pandemic, adult men were more physically active and more involved in team sports than women (Azevedo et al. 2007; Tuyckom et al. 2010). Among youth, males were more likely to participate in school-sponsored sports than females (National Federation of State High School Associations 2016; ChildTrends 2017). As a result, men may have been more likely to perceive COVID-19 as a threat to their normal physical activity routines. With school closures, many youth sports were cancelled or postponed. Major sports leagues such as the National Hockey League cancelled their seasons, as did minor leagues. Social distancing and stay-at-home orders further limited team sports involvement. Men, as a demographic group, may have been able to offset the lack of team sports with other physical activities. However, they may have been more likely to perceive COVID-19 as a barrier to team and group activities more commonly frequented by males than females.

A final demographic difference was that rural residents were about half as likely to see COVID-19 as a barrier to physical activity. Unlike urban residents, those in rural areas may have more immediate access to green spaces and outdoor recreation than those in urban areas. Use of these spaces was largely unaffected by COVID-19 public health regulations. When gyms and other indoor facilities closed, rural residents might have been more likely to identify and recognize other opportunities to stay active. This study found that the ruralurban difference emerged particularly for perceptions of the pandemic as a barrier to child activity. On average, rural residents typically have lower household incomes than their urban and suburban counterparts. Lareau (2003) observed that working class parents were more likely than middle class parents to encourage their children to take part in unstructured activities, those least affected by the pandemic. Children from lower-income households are less likely to be active and less likely to participate in school-sponsored sports (Aspen Institute 2017; Physical Activity Council 2020). Loss of school-sponsored opportunities due to COVID-19 might seem like less of a barrier to being active as a consequence.

\section{Practical impact and directions for further study}

Aside from the few examples just discussed, the key message from this study appears to be one of consistent impact, not disparate impact. Decreases in physical activity spanned across demographic groups; nearly a third of the sample reported decreases in physical activity for themselves or their child. Pennsylvania residents were also highly likely to perceive COVID-19 as a barrier to their physical activity even if they were likely to find other avenues to stay active. These 
changes are troublesome. Exercise is a key factor in maintaining a healthy weight (Petridou et al. 2019); obesity is common in the U.S. (Hayles et al. 2020). It is already known that most Americans do not meet the recommended minimum amount of physical activity each week (Piercy et al. 2018). Additionally, moderate exercise reduces a person's likelihood of infection or becoming sick (Gleeson and Walsh 2012), a key concern in the midst of a global pandemic. It remains unclear what other steps individuals and families may be taking to stay healthy, including changes in diet and hygiene.

A critical practical concern is whether decreases in physical activity will persist long-term. Developing a strong exercise habit increases the likelihood that a person will continue to exercise even with short-term interruptions due to illness, injury, holidays, or other factors (Rebar et al. 2020). Developing an inactivity habit may be difficult to overcome. This tendency may be compounded by fears of disease spread or concerns about cleanliness that could persist long after the pandemic ends. Further study after the pandemic is needed to assess return to physical activity among the inactive and remaining perceptions of barriers. Identifying these may pinpoint areas for intervention, such as efforts to educate individuals on how they can stay active at home. Additionally, it is important to determine how the economic impact of the pandemic may impact sports participation. Those with lower income are already less likely to be active and participate in sports (Aspen Institute 2017; Physical Activity Council 2020). An economic downturn may widen the participation divide.

\section{Limitations}

This study has several characteristics that may limit the ability to generalize from results. First, the sample was drawn exclusively from Pennsylvania. Inferences for other states or regions cannot be drawn, especially since responses to COVID-19 varied widely state to state. Second, the sample was obtained through a market research panel. Although Qualtrics used quotas and targeted recruiting to align sample demographics with those for the state as a whole, individuals who choose to take surveys for points or other incentives may differ from residents more broadly. Women and White individuals were overrepresented, as were parents whose oldest or only child was male. It is possible that the title of the survey, Athletics and Parenting, was somehow more appealing to these individuals than others. The study did not track physical activity precisely over time, relying on selfreports of change instead. Respondent recall is prone to error. The study did not explore which specific types of exercise or sports were more prone to change due to the pandemic. Lastly, respondents self-identified whether they lived in a rural area or not. Their self-reports may not be accurate to more objective measures of rurality.

\section{Conclusion}

This study investigated how COVID-19 impacted the physical activity and sports participation of Pennsylvania residents and their children. Other sources had identified examples of disparate impact in employment and mortality based on factors such as race, ethnicity, socioeconomic status, and gender. This study found only limited evidence of varied impact on physical activity, suggesting that COVID-19 reduced physical activity among individuals across demographic subgroups. In this context, COVID-19 was largely a leveling force. This study also found that changes in physical activity and perceptions of COVID-19 as a barrier to physical activity were distinct constructs. Men, in particular, were more likely to perceive COVID-19 as a barrier even though there was no gender difference in actual changes in physical activity. The results of this study underscore the profound impact of the COVID-19 pandemic on our health as a nation. Exercise, in all forms, plays a key role in overall health, weight, and disease resistance. It remains unclear how declines in physical activity might persist over time, and among whom.

Authors' contributions The author is the sole author of the manuscript and was responsible for all writing, design, and analysis.

Funding This study was funded by a 2019-2020 grant from the Penn State Center for the Study of Sports in Society.

Availability of data and material Not applicable - data are not approved for release by the institution's IRB.

Code availability Not applicable.

\section{Declarations}

Ethics approval All procedures and materials for this study were approved by the Penn State IRB prior to study implementation.

Consent to participate All participants read an informed consent document and indicated their consent to proceed with the survey by selecting yes to the statement, "I have read the informed consent document and agree to participate of my own free will in this study."

Consent for publication Not applicable.

Conflict of interest The author has no conflicts of interest to report.

\section{References}

SHAPE America (2016) 2016 shape of the Nation: status of physical education in the USA. Society of Health and Physical Educators. https://www.shapeamerica.org/advocacy/son/

Aspen Institute (2017) State of play 2017: trends and developments. https://www.aspeninstitute.org/publications/state-of-play-2017trends-and-developments/ 
Azevedo MR, Araújo CLP, Reichert FF et al (2007) Gender differences in leisure-time physical activity. Int J Public Health 52:8-15. https:// doi.org/10.1007/s00038-006-5062-1

Brand R, Timme S, Nosrat S (2020) When pandemic hits: exercise frequency and subjective well-being during COVID-19 pandemic. Front Psychol 11:570567. https://doi.org/10.3389/fpsyg.2020. 570567

Calo WA, Murray A, Francis E, et al (2020) Reaching the Hispanic community about COVID-19 through existing chronic disease prevention programs. US Public Health Response COVID-19 Chronic Dis Spec Suppl 17:E49

Centers for Disease Control and Prevention (2018) Youth Online: High School YRBS. https://nccd.cdc.gov/youthonline/App/Default.aspx. Accessed 22 Jun 2018

ChildTrends (2017) Participation in school athletics. https://www. childtrends.org/indicators/participation-in-school-athletics\#: :text= Participation \%20in\%20school\%20athletics\%20among,in\% 202017\%20(Appendix\%201).

Choi C, Bum C-H (2020) Changes in the type of sports activity due to COVID-19: hypochondriasis and the intention of continuous participation in sports. Int J Environ Res Public Health 17:4871. https:// doi.org/10.3390/ijerph17134871

Day M, Loewenstein MA, Piccone Jr. DS, Polivka AE (2020) Demographics, earnings, and family characteristics of workers in sectors initially affected by COVID-19 shutdowns: monthly labor review. U.S. Bureau of Labor Statistics. https://www.bls.gov/opub/ $\mathrm{mlr} / 2020 /$ article/demographics-earnings-and-family-characteristicsof-workers-in-sectors-initially-affected-by-covid-19-shutdowns. $\mathrm{htm}$

Dynarski S (2018) Online courses are harming the students who need the most help. N.Y. Times. https://www.nytimes.com/2018/01/19/ business/online-courses-are-harming-the-students-who-need-themost-help.html

Gleeson M, Walsh NP (2012) The BASES expert statement on exercise, immunity, and infection. J Sports Sci 30:321-324. https://doi.org/ 10.1080/02640414.2011.627371

Hawes AM, Smith GS, McGinty E et al (2019) Disentangling race, poverty, and place in disparities in physical activity. Int J Environ Res Public Health 16:1193. https://doi.org/10.3390/ijerph16071193

Hayles CM, Carroll MD, Fryar CD, Ogden CL (2017) Prevalence of obesity among adults and youth: United States, 2015-2016. NCHS Data Brief(288):1-8.

Hayles CM, Carroll MD, Fryar CD, Ogden CL (2020) Prevalence of obesity and severe obesity among adults: United States, 2017 2018. https://www.cdc.gov/nchs/products/databriefs/db360.htm

He XZ, Baker DW (2005) Differences in leisure-time, household, and work-related physical activity by race, ethnicity, and education. J Gen Intern Med 20:259-266. https://doi.org/10.1111/j.1525-1497. 2005.40198.x

Karageorge EX (2020) COVID-19 recession is tougher on women : Monthly Labor Review: U.S. Bureau of Labor Statistics. https:// www.bls.gov/opub/mlr/2020/beyond-bls/covid-19-recession-istougher-on-women.htm. Accessed 30 Nov 2020

Lam CB, McHale SM, Crouter AC (2012) Parent-child shared time from middle childhood to late adolescence: developmental course and adjustment correlates. Child Dev 83:2089-2103
Lareau A (2003) Unequal childhoods: class, race, and family life. University of California Press, Berkeley

Meszaros L (2019) What's the healthiest country in the world? In: MDLinx. https://www.mdlinx.com/article/what-s-the-healthiestcountry-in-the-world/lfc-3613. Accessed 17 Nov 2020

Mutz M, Gerke M (2021) Sport and exercise in times of self-quarantine: how Germans changed their behaviour at the beginning of the Covid-19 pandemic. Int Rev Sociol Sport 56:305-316. https://doi. org/10.1177/1012690220934335

National Federation of State High School Associations (2016) Participation Statistics. http://www.nfhs.org/ParticipationStatics/ ParticipationStatics.aspx/. Accessed 22 Jun 2018

Petridou A, Siopi A, Mougios V (2019) Exercise in the management of obesity. Metabolism 92:163-169. https://doi.org/10.1016/j.metabol. 2018.10.009

Pew Research Center (2020) Health concerns from COVID-19 much higher among Hispanics and Blacks than Whites. In: Pew Res. Cent. - US Polit. Policy. https://www.pewresearch.org/politics/ 2020/04/14/health-concerns-from-covid-19-much-higher-amonghispanics-and-blacks-than-whites/. Accessed 2 Dec 2020

Physical Activity Council (2020) 2020 Physical Activity Council's overview report on U.S. participation. http://www. physicalactivitycouncil.com/

Piercy KL, Troiano RP, Ballard RM et al (2018) The physical activity guidelines for Americans. JAMA 320:2020. https://doi.org/10.1001/ jama.2018.14854

Poulain T, Meigen C, Sobek C et al (2021) Loss of childcare and classroom teaching during the Covid-19-related lockdown in spring 2020: a longitudinal study on consequences on leisure behavior and schoolwork at home. PLoS One 16:e247949. https://doi.org/ 10.1371/journal.pone.0247949

Rebar AL, Gardner B, Verplanken B (2020) Habit in exercise behavior. In: Handbook of sport psychology. Wiley, New York, pp 986-998

Rosner B (2015) Fundamentals of biostatistics, 8th edn. Cengage Learning, Boston, MA

Stults-Kolehmainen MA, Sinha R (2014) The effects of stress on physical activity and exercise. Sports Med 44:81-121. https://doi.org/10. 1007/s40279-013-0090-5

Tuyckom CV, Scheerder J, Bracke P (2010) Gender and age inequalities in regular sports participation: a cross-national study of 25 European countries. J Sports Sci 28:1077-1084. https://doi.org/10.1080/ 02640414.2010 .492229

U.S. Census Bureau (2019) U.S. Census Bureau QuickFacts: Pennsylvania. https://www.census.gov/quickfacts/fact/table/pa,US/ PST045218. Accessed 19 Mar 2019

Vogels EA (2020) About one-in-five Americans use a smart watch or fitness tracker. In: Pew Res. Cent. https://www.pewresearch.org/ fact-tank/2020/01/09/about-one-in-five-americans-use-a-smartwatch-or-fitness-tracker/. Accessed 30 Nov 2020

Publisher's note Springer Nature remains neutral with regard to jurisdictional claims in published maps and institutional affiliations. 